\title{
Effect of Mental Stress on Plasma Homovanillic Acid in Healthy Human Subjects
}

Tomiki Sumiyoshi, M.D., Ph.D., Takashi Yotsutsuji, M.D., Masayoshi Kurachi, M.D., Ph.D., Hiroko Itoh, B.C., Kenzo Kurokawa, M.D., Ph.D., and Osamu Saitoh, M.D., Ph.D.

Plasma levels of homovanillic acid ( $p H V A$ ) have been suggested to provide a measure of dopaminergic activity in the central nervous system. The present study investigated the effect of mental stress by the Kraepelin test, a test of continuous arithmetic addition of single-digit figures for 30 min, on $\mathrm{pHVA}$ levels in 13 male psychiatrically normal healthy volunteers. Following an overnight fast and restricted physical activity, plasma samples were collected immediately before and after the administration of the Kraepelin test. Plasma HVA levels following the administration of the Kraepelin test were significantly lower than the pretest $p H V A$ levels. The percent change in $p H V A$ levels by the Kraepelin test positively correlated with pretest $p H V A$ levels. The observed reduction in $p H V A$ levels by mental stress in normal subjects may reflect some aspects of a dopamine-dependent restitutive system in the brain. [Neuropsychopharmacology 19:70-73, 1998] (C) 1998 American College of Neuropsychopharmacology. Published by Elsevier Science Inc.
KEY WORDS: Plasma homovanillic acid; $p H V A$; Kraepelin test; Mental stress; Human

Plasma levels of homovanillic acid (pHVA), a major metabolite of dopamine (DA), have been used as a peripheral measure of dopaminergic activity in the central nervous system (Bacopoulas et al. 1979; Kendler et al. 1981; Kendler et al. 1982). Although a relatively small part of pHVA has been indicated as central origin (Kopin et al. 1988; Maas et al. 1988; Lambert et al. 1993), there have been reports of the usefulness of pHVA as a peripheral indicator of central dopaminergic activity (Pickar et al. 1990; Stroe et al. 1997). Thus, a vast number of studies have been conducted to relate pHVA levels with some aspects of such mental disorders as

From the Department of Neuropsychiatry, Toyama Medical and Pharmaceutical University, School of Medicine, Toyama, Japan.

Address correspondence to: Tomiki Sumiyoshi, M.D., Ph.D., Department of Neuropsychiatry, Toyama Medical and Pharmaceutical University, School of Medicine, 2630 Sugitani, Toyama, 9300194 Japan.

Received 18 July 1997; revised 10 December 1997; accepted 16 December 1997. schizophrenia. For example, the ability of pHVA levels to predict response to treatment with typical (Chang et al. 1993; Davilia et al. 1988; Davis et al. 1985; Pickar et al. 1984; Suzuki et al. 1994) and atypical (Green et al. 1993; Sumiyoshi et al. 1997a) neuroleptics has been tested in subjects with schizophrenia.

Diet (Kendler et al. 1983), physical activity (Kendler et al. 1983), circadian fluctuation (Zumarraga et al. 1993) or gender difference (Sumiyoshi et al. 1997b) have been suggested to affect pHVA concentrations. However, there has been little study of the effect of mental stress on pHVA levels. Previous studies report altered blood or urinary levels of catecholamines attributable to mental stress in humans (Januszewicz et al. 1979; Frankenhaeuser et al. 1985; Rauste-von Wright and Frankenhaeuser 1989). Changes in DA-dependent behaviors attributable to mental stress have been reported in laboratory animals (Friedhoff et al. 1995). These findings suggest a significant effect of mental stress on pHVA levels.

The present study was undertaken to test the hypothesis that mental stress resulting from the Kraepelin's arithmetic test would significantly decrease pHVA levels in psychiatrically well normal subjects. 


\section{SUBJECTS AND METHODS}

Thirteen male psychiatrically normal healthy volunteers (mean $\pm \mathrm{SD}$ age $=29.0 \pm 3.1$; range $24-34$ years), who gave written consent to the study were investigated. DSM-IV Axis I disorders were ruled out for these subjects using a structured interview by experienced psychiatrists taking medical histories. Physical exercise, high monoamine diets, alcohol, and caffeine were restricted for all subjects from the start of the study $(>24 \mathrm{~h}$ before blood sampling).

The subjects performed a modified version of Kraepelin's arithmetic test (Uchida-Kraepelin test) (Kuraishi et al. 1957), a test of continuous arithmetic addition for $30 \mathrm{~min}$, which has been used in neurophysiological (Mizuki et al. 1980; Takii 1986) and neuropharmacological (Murasaki et al. 1989) studies. Pretest blood sampling was performed through an intravenous line at 9:00 A.M. on the day of investigation following an overnight fast. The subjects rested after the venous line was inserted. Immediately after the pretest blood sampling, the subjects began to add each of overlapping sequential pairs of single digit numbers (the second number of one pair becomes the first number of the following pair). The last digit of the sum of each pair was written in a space just below each pair. The numbers on the test sheet were written in such a manner that the subjects changed to a new line of numbers every $1 \mathrm{~min}$. Immediately after termination of arithmetic addition for 30 lines (30 min after the pretest blood sampling), blood samples were again collected for measurement of the posttest pHVA levels. Plasma was separated by centrifugation and stored at $-80^{\circ} \mathrm{C}$ until the free HVA was measured.

Plasma HVA analysis was carried out by high-performance liquid chromatography (HPLC) with coulo-

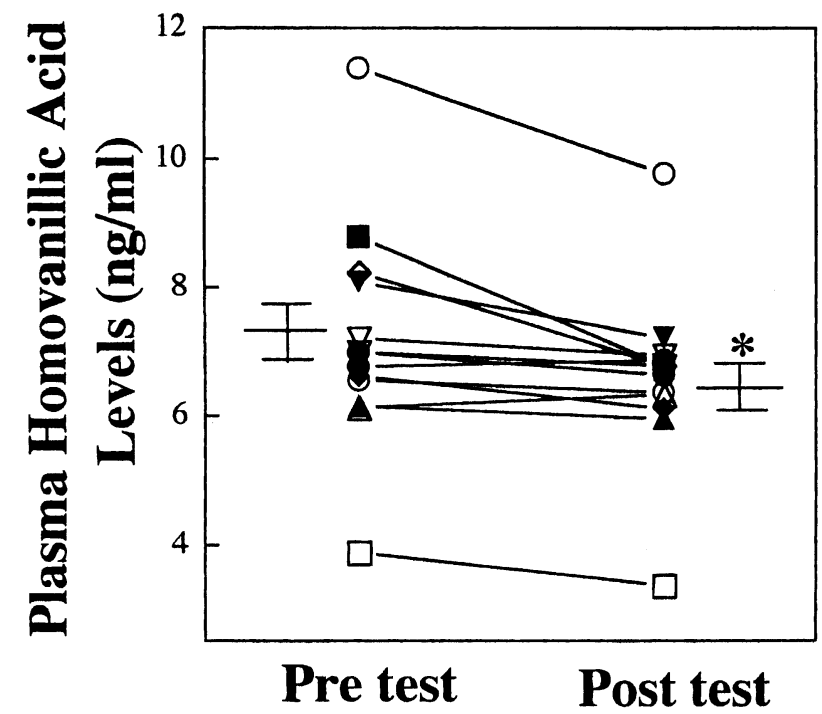

Figure 1. Plasma homovanillic acid levels (mean \pm SEM $\mathrm{ng} / \mathrm{ml}$ ) before and after Kraepelin's arithmetic test, ${ }^{*} p<.01$. metric detection using d.1.-isoproterenol as internal standard. The coefficients of variation $(\mathrm{CV})$ for within day $(n=6)$ and between day $(n=6)$ analyses of pHVA were 2.4 and $3.3 \%$, respectively.

Pre- and post-Kraepelin test pHVA levels were compared by nonparametric Wilcoxon signed rank test. Spearman's correlation coefficients were obtained relating pretest pHVA levels with percentage changes in pHVA levels as well as with changes in pHVA values (calculated by subtracting post-test pHVA levels from pretest pHVA levels). Differences were considered to be significant when $p$-values were less than .05 .

\section{RESULTS}

Figure 1 shows pHVA levels in blood samples collected before and after the administration of the Kraepelin test. The post-test value of pHVA levels was significantly less than the pretest value $(p=.0046)$.

Figure 2 demonstrates the correlation between the pretest pHVA levels and percentage changes in pHVA levels for each subject. The percentage change in pHVA levels following the Kraepelin test correlated positively with pretest $\mathrm{pHVA}$ levels $\left(r_{s}=0.63, p=.029\right)$. Changes in the pHVA levels themselves during the Kraepelin test also correlated with pretest $\mathrm{pHVA}$ levels $\left(r_{s}=0.74\right.$, $p=.011$; data not shown).

\section{DISCUSSION}

The present study provided the first evidence that mental stress by use of Kraepelin's arithmetic test decreases

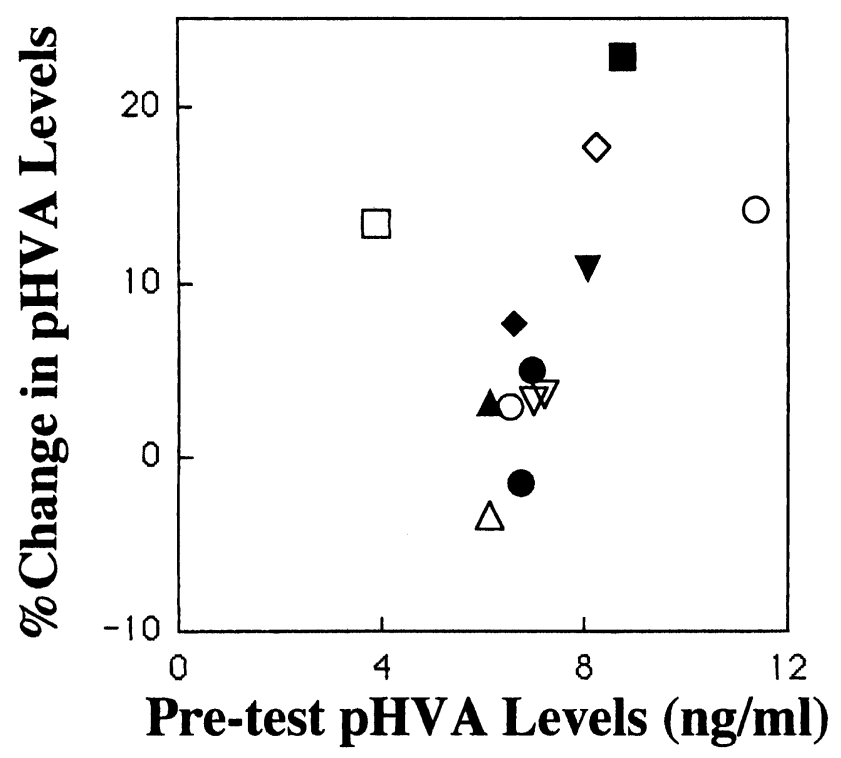

Figure 2. Correlation between pre-Kraepelin test pHVA levels and percentage changes in pHVA levels (ng/ml). 
pHVA levels in healthy subjects (Figure 1). The significant effect of mental stress on pHVA levels may be one of the factors responsible for the inconsistent results in previous studies reporting increased, decreased, or normal pHVA levels in subjects with schizophrenia as compared to normal controls (see Sumiyoshi et al. 1997b for review).

Previous studies investigating the effect of physical or mental stress generally have focused on changes in blood or urinary levels of adrenaline, noradrenaline (NE) or their metabolites (Halbrugge et al. 1988; Januszewicz et al. 1979). The observed decrease in pHVA levels caused by mental stress could be explained by both central and peripheral events. Increased urinary HVA and DA concentrations have been found after mental or emotional stress (Fibiger and Singer 1984; Frankenhaeuser et al. 1985; Rauste-von Wright and Frankenhaeuser 1989). The present version of Kraepelin's arithmetic test (Uchida-Kraepelin test) requires intellectual ability to the extent that subjects taking diazepam (20 mg/day) show marked deterioration in performance (Murasaki et al. 1989). Januszewicz et al. (1979) examined the effect of Kraepelin's arithmetic test on blood and urinary catecholamine concentrations. In that study, increased NE and 3-methoxy-4-hydroxyphenylglycol concentrations in urine as well as increased blood NE levels were observed in healthy subjects following Kraepelin's test (Januszewicz et al.). Thus, it is possible that similar mechanism(s) (e.g., changes in urinary excretion) underlying altered output of these catecholamines and metabolites may, in some way, be associated with the decrease in pHVA levels in subjects suffering from mental stress.

Changes in the central dopaminergic activity by mental stress may also be a factor to explain the observed decrease in pHVA levels. Dopaminergic activity in subcortical brain regions such as nucleus accumbens has been suggested to contribute to patterns of pHVA change (Csernansky et al. 1990). Dopamine utilization expressed as HVA/DA concentrations in nucleus accumbens is decreased in rats receiving chronic witness stress (Friedhoff et al. 1995). Also in line with the present result is a recent finding that mental stress is associated with a reduction in extracellular DA release in the rat striatum (Katoh et al. 1996). Friedhoff (1986, 1988) and Friedhoff et al. (1995) have proposed the presence of a DA-dependent protective system in the brain that maintains mental stability in the face of biological or psychological insult. They predicted that a role of the dopaminergic system is to reduce the risk of mental decompensation (disruption of mental stability in the face of changing environmental contingencies) during stress by decreasing its own activity. They proposed this occurs in normal subjects or a part of schizophrenic patients and would be reflected in pHVA levels as was observed here (Friedhoff 1986, 1988; Friedhoff et al. 1995). Thus, the reduction in pHVA levels by mental stress reported here is consistent with the hypothesis of Friedhoff et al. (1995). In this context, the positive correlation between baseline (pretest) pHVA levels and percentage changes in pHVA levels during the mental stress test (Figure 2) may suggest that subjects with higher pHVA level have a greater ability to cope with psychological stress. This finding may have relevance to the reported correlations between higher baseline (pretreatment) pHVA level and better therapeutic outcome in schizophrenic patients who receive neuroleptic treatment (Chang et al. 1993; Green et al. 1993; Sumiyoshi et al. 1997a). To further clarify the clinical significance of the present results, studies investigating the effect of mental stress on pHVA levels in subjects with schizophrenia are in progress.

The study design did not employ a control group. Because the version of Kraepelin test used here takes only $30 \mathrm{~min}$, it is unlikely that significant change in pHVA would occur in the absence of stress. The stability of pHVA levels has been established in normal subjects (Kendler et al. 1983) and patients with schizophrenia (Donnelly et al. 1996) based on data from plasma sampling over a several hour period including the morning. However, inclusion of data from unstressed subjects could have ruled out a possible change in pHVA related to time.

In conclusion, we have reported a reduction in pHVA levels by mental stress in psychiatrically normal subjects. This finding may reflect some aspects of a DAdependent restitutive system in the brain, although peripheral contribution to the decrease in pHVA levels should also be considered.

\section{ACKNOWLEDGMENTS}

A part of this work was presented at the 27th Annual Meeting of Society for Neuroscience in November, 1997, in New Orleans, Louisiana, USA. We thank Dr. Herbert Y. Meltzer, MD for fruitful discussion.

\section{REFERENCES}

Bacopoulas NG, Hattox SE, Roth RH (1979): 3,4-Dihydroxyphenylacetic acid and homovanillic acid in rat plasma: Possible indicators of central dopaminergic activity. Eur J Pharmacol 56:225-236

Chang W-H, Hwu H-G, Chen T-Y, Lin S-K, Lung F-W, Chen H, Lin W-L, Hu W-H, Lin H-N, Chien C-P (1993): Plasma homovanillic acid and treatment response in a large group of schizophrenic patients. Schizophr Res 10:259-265

Csernansky JG, Barnes DE, Bellows EP, Lombrozo J (1990): Interrelationships between plasma homovanillic acid and indices of dopamine turnover in multiple brain 
areas during haloperidol and saline administration. Life Sci 46:707-713

Davilia R, Manero E, Zumarraga M, Andia I, Schweitzer JW, Friedhoff AJ (1988): Plasma homovanillic acid as a predictor of response to neuroleptics. Arch Gen Psychiatry 45:564-567

Davis KL, Davidson M, Mohs RC, Kendler KS, Davis BM, Johns CA, DeNigris Y, Horvath TB (1985): Plasma homovanillic acid concentration and the severity of schizophrenic illness. Science 227:1601-1602

Donnelly CL, McEvoy JP, Wilson WH, Narasimhachari N (1996): A study of the potential confounding effects of diet, caffeine, nicotine, and lorazepam on the stability of plasma and urinary homovanillic acid levels in patients with schizophrenia. Biol Psychiatry 40:1218-1221

Fibiger W, Singer G (1984): Urinary dopamine in physical and mental effort. Eur J Appl Physiol 52:437-440

Frankenhaeuser M, Lundberg U, Rauste von Wright M, von Wright J, Sedvall G (1985): Urinary monoamine metabolites as indices of mental stress in healthy male and females. Pharmacol Biochem Behav 24:1521-1525

Friedhoff AJ (1986): A dopamine-dependent restitutive system for the maintenance of mental normalcy. In Burrell CD, Strand FL (eds), Second Colloquium in Biological Sciences. New York, Ann NY Acad Sci Volume 463, pp 47-52

Friedhoff AJ (1988): Dopamine as a mediator of a central stabilizing system. Neuropsychopharmacology 1:189-191

Friedhoff AJ, Carr KD, Uysal S, Schweitzer J (1995): Repeated inescapable stress produces a neuroleptic-like effect on the conditioned avoidance response. Neuropsychopharmacology 13:129-138

Green AI, Alam MY, Sobieraj JT, Pappalardo KM, Waternaux C, Saltzman C, Schatzberg AF, Schildkraut JJ (1993): Clozapine response and plasma catecholamines and their metabolites. Psychiatry Res 46:139-149

Halbrugge T, Gerhardt T, Ludwig J, Heidbreder E, Graefe K-H (1988): Assay of catecholamines and dihydroxyphenylethyleneglycol in human plasma and its application in orthostasis and mental stress. Life Sci 43:19-26

Januszewicz W, Sznajderman M, Wocial B, Feltynowski T, Klonowicz T (1979): The effect of mental stress on catecholamines, their metabolites, and plasma renin activity in patients with essential hypertension and in healthy subjects. Clin Sci 57:229s-231s

Katoh A, Nabeshima T, Kuno A, Wada M, Ukai R, Kameyama T (1996): Changes in striatal dopamine release in stress-induced conditioned suppression of motility in rats. Behav Brain Res 77:219-221

Kendler KS, Heninger GR, Roth RH (1981): Brain contribution to the haloperidol-induced increase in plasma homovanillic acid. Eur J Pharmacol 71:321-326

Kendler KS, Heninger GR, Roth RH (1982): Influence of dopamine agonists on plasma and brain levels of homovanillic acid. Life Sci 30:2063-2069

Kendler KS, Mohs RC, Davis KL (1983): The effect of diet and physical activity on plasma homovanillic acid in normal human subjects. Psychiatry Res 8:215-223
Kopin IJ, Bankiewicz KS, Harvey-White J (1988): Assessment of brain dopamine metabolism from plasma HVA and MHPG during debrisoquin treatment: Validation in monkeys treated with MPTP. Neuropsychopharmacology 1:119-125

Kuraishi S, Kato M, Tsujioka B (1957): Development of the "Uchida-Kraepelin psychodiagnostic test" in Japan. Psychologia 1:104-109

Lambert GW, Eisenhofer G, Jennings GL, Esler MD (1993): Regional homovanillic acid production in human. Life Sci 53:63-75

Maas JW, Contreas SA, Seleshi E, Bowden CL (1988): Dopamine metabolism and disposition in schizophrenic patients: studies using debrisoquin sulfate. Arch Gen Psychiatry 45:553-559

Mizuki Y, Tanaka M, Isozaki H, Nishijima H, Inanaga K (1980): Periodic appearance of theta rhythm in the frontal midline area during performance of a mental task. Electroenceph Clin Neurophysiol 49:345-351

Murasaki M, Miura S, Ishigooka J (1989): Phase I study of a new antianxiety drugs, buspirone. Prog Neuro-Psychopharmacol \& Biol Psychiat 13:137-144

Pickar D, Labarca R, Linnoila M, Roy A, Hommer D, Everett D, Paul SM (1984): Neuroleptic-induced decrease in plasma homovanillic acid and antipsychotic activity in schizophrenic patients. Science 225:954-957

Pickar D, Breier A, Hsiao JK, Doran AR, Wolkowitz OM, Pato CN, Konicki PE, Potter WZ (1990): Cerebrospinal fluid and plasma monoamine metabolites and relation to psychosis. Arch Gen Psychiatry 47:641-648

Rauste-von Wright M, Frankenhaeuser M (1989): Females' emotionality as reflected in the excretion of the dopamine metabolite HVA during mental stress. Psychol Rept 64: 856-858

Stroe AE, Amin F, Hashimi A, Densmore D, Kahn T, Knott PJ (1997): Diurnal variation in plasma homovanillic acid: Not a renal phenomenon. Biol Psychiatry 41:621-623

Sumiyoshi T, Hasegawa M, Jayathilake K, Meltzer HY (1997a): Prediction of short-term changes in symptom severity by baseline plasma homovanillic acid levels in schizophrenic patients receiving clozapine. Psychiatry Res 69:113-121

Sumiyoshi T, Hasegawa M, Jayathilake K, Meltzer HY (1997b): Sex differences in plasma homovanillic acid levels in schizophrenia and normal controls: Relation to neuroleptic resistance. Biol Psychiatry 41:560-566

Suzuki E, Shigenobu K, Nibuya M, Adachi S, Sekiya U, Shintani F, Kinoshita N, Yagi G, Asai M (1994): Longitudinal change in symptoms and plasma homovanillic acid levels in chronically medicated schizophrenic patients. Biol Psychiatry 36:654-661

Takii O (1986): Diurnal rhythm in appearance of frontal midline theta activity. Jap J Psychiat Neurol 40:609-615

Zumarraga M, Andia I, Barcena B, Gonzalez-Torres M, Davila R (1993): Morning variations of plasma homovanillic acid in untreated schizophrenic patients. J Psychiat Res 27:11-16 